\title{
A stable isotope study of zinc kinetics in Irish setters with gluten-sensitive enteropathy
}

\author{
BY N. M. LOWE ${ }^{*}$, E. J. HALL ${ }^{2}$, R. S. ANDERSON ${ }^{3}$, R. M. BATT ${ }^{2} \dagger$ AND \\ M. J. JACKSON ${ }^{1}$ \\ Departments of ${ }^{1}$ Medicine, ${ }^{2}$ Veterinary Pathology and ${ }^{2}$ Veterinary Clinical Science and Animal \\ Husbandry, University of Liverpool, PO Box 147, Liverpool L69 $3 B X$
}

(Received 8 August 1994 - Revised 3 November 1994 - Accepted 6 December 1994)

\begin{abstract}
The short-term kinetics of $\mathrm{Zn}$ turnover were studied in Irish setters with gluten-sensitive enteropathy and control dogs following intravenous injection of $0.25 \mathrm{mg} 96.5 \%$ enriched ${ }^{70} \mathrm{ZnCl}_{2}$. The ${ }^{70} \mathrm{Zn}$ enrichment of serum was found closely to obey two-compartment kinetics and the derived two-compartment decay equation was used to calculate the size and turnover of the two initial rapidly exchanging pools of body $\mathrm{Zn}$. In normal Irish setters isotopic Zn initially equilibrates with a pool (a) of size 1.27 (SD 0.46) $\mu \mathrm{mol} / \mathrm{kg}$ and then with a second pool (b) of size 6.83 (SD 1.72) $\mu \mathrm{mol} / \mathrm{kg}$. The fractional turnover of pool (b) was approximately one eighth that of pool (a). Enteropathic dogs showed no reduction in the size of either rapidly exchangeable $\mathrm{Zn}_{\mathbf{n}}$ pool, reduction in serum $\mathrm{Zn}$ concentration or abnormality in $\mathrm{Zn}$ balance and hence these results do not support the possibility of an underlying $\mathrm{Zn}$ deficiency in this disorder.
\end{abstract}

Zinc: Gluten-sensitive enteropathy: Dog

The assessment of $\mathrm{Zn}$ status is complicated because of the lack of accessible tissues which reflect overall body $\mathrm{Zn}$ content (Jackson et al. 1982; Golden, 1989) and because plasma or serum $\mathrm{Zn}$ concentrations are recognized to vary in stress conditions unassociated with $\mathrm{Zn}$ deficiency (Hallbrook \& Hedelin, 1977). Various workers have attempted to utilize isotopic techniques to overcome this problem (Jackson et al. 1988; Lowe et al. 1991, 1992, 1993), but techniques for the application of isotopes to the routine study of $\mathrm{Zn}$ metabolism in dogs do not appear to have been described.

Radioactive isotopes of $\mathrm{Zn}$ have been used to develop complex mathematical models which describe $\mathrm{Zn}$ kinetics under various conditions in man and laboratory animals (Foster et al. 1979; Henkin et al. 1984; Wastney et al. 1986; Dunn \& Cousins, 1989). Such models have been used to help identify sites of regulation of $\mathrm{Zn}$ metabolism and calculate the size and turnover rate of body $\mathrm{Zn}$ pools. A simpler model describing $\mathrm{Zn}$ kinetics over a short time period ( $90 \mathrm{~min}$ ) has been developed using ${ }^{65} \mathrm{Zn}$ in the rat (Lowe et al. 1991). Using this model it was shown that a rapidly exchanging pool of $\mathrm{Zn}$ is responsive to changes in dietary $\mathrm{Zn}$ intake, becoming significantly depleted in animals maintained on a $\mathrm{Zn}$-deficient diet. ${ }^{65} \mathrm{Zn}$ is a gamma emitter with a biological half-life of over $500 \mathrm{~d}$ (Hawkins et al. 1976). Due to safety considerations, its applicability in the study of $\mathrm{Zn}$ metabolism in domestic animals, such as dogs, is debatable.

Recent studies have shown that stable $\mathrm{Zn}$ isotopes can be used to study $\mathrm{Zn}$ kinetics in man (Jackson et al. 1984; Lowe et al. 1992, 1993; Miller et al. 1994) and such techniques are likely to be applicable to the dog.

* Present address: Department of Nutritional Sciences, University of California, Berkeley CA 94720, USA.

† Present address: Department of Clinical Veterinary Medicine, Royal Veterinary College, Hawkshead Lane, North Mimms, Hatfield, Herts AL9 7TA.

$\ddagger$ For reprints. 
Gluten-sensitive enteropathy is a naturally occurring familial condition of Irish setter dogs manifested histologically by partial villus atrophy and intraepithelial lymphocyte infiltration (Hall \& Batt, 1990a). An underlying abnormality of intestinal permeability has been reported (Hall \& Batt, 1991). The disease resembles coeliac disease in humans because recovery is possible if affected dogs are maintained on a gluten-free diet, and relapse occurs when dogs are orally challenged with gluten (Hall \& Batt, 1992). Although there are no overt signs of $\mathbf{Z n}$ deficiency in affected setters the finding of secondary but specific biochemical abnormalities, particularly reduced activities of $\mathrm{Zn}$-containing enzymes such as alkaline phosphatase (EC 3.1.3.1) and aminopeptidase $\mathrm{N}(E C 3.4 .11 .2)$, led to the hypothesis that impaired nutrient absorption may cause marginal $\mathrm{Zn}$ deficiency (Hall \& Batt, 1990 b). Findings of depleted body $\mathrm{Zn}$ pools in affected setters would support this hypothesis.

In the present study stable-isotope techniques have been used to study $\mathrm{Zn}$ turnover in Irish setter dogs. A simple kinetic model (based on that previously developed for rats and applied to human studies, Lowe et al. 1991, 1993) has been derived to describe the isotopic $\mathrm{Zn}$ turnover over $2 \mathrm{~h}$ post-injection of ${ }^{70} \mathrm{Zn}$. This has enabled the size and turnover rate of two rapidly exchanging $\mathrm{Zn}$ pools to be calculated. The technique was then applied to measure these variables in dogs with gluten-sensitive enteropathy. This information, along with the more commonly used indicators of $\mathrm{Zn}$ status, plasma $\mathrm{Zn}$ levels and $\mathrm{Zn}$-balance measurements, has been used to evaluate the possibility that enteropathic animals may be marginally $\mathrm{Zn}$ deficient.

\section{MATERIALS AND METHODS}

Animals

Twelve Irish setter dogs aged 1-5-7 years were studied. Six of the dogs (four male and two female, aged 2-5 years) were healthy controls, the remaining six (five male, one female, aged 1.5-7 years) had been shown to be suffering from gluten-sensitive enteropathy by response to gluten withdrawal and relapse on gluten challenge (Hall \& Batt, 1992). The animals were routinely maintained on a gluten-containing diet and were given known amounts for $3 \mathrm{~d}$ before the kinetic study. The diet was composed of a known quantity of cereal mixer (Pedigree Chum mixer; Pedigree Petfoods, Melton Mowbray, Leicester, Leics.) and tinned meat ('Caesar'; Pedigree Petfoods). In order to determine the Zn content a sample of each meat portion and of the batch of mixer used were wet-ashed in concentrated $\mathrm{HNO}_{3}$. After dilution with deionized distilled water the $\mathrm{Zn}$ content was determined by atomic absorption spectrometry.

\section{Kinetic study}

After the $3 \mathrm{~d}$ equilibration period on the controlled diet a cannula (19G Intracath; Dorset Medical Inc., Utah, USA) was inserted into the jugular vein of the dog and a baseline blood sample $(10 \mathrm{ml})$ taken. A $0.25 \mathrm{mg}$ portion of $96.5 \%$ enriched ${ }^{70} \mathrm{ZnCl}_{2}$ (Oakridge National Laboratory, Oakridge, TN, USA) in $5 \mathrm{ml}$ isotonic sterile saline $(9 \mathrm{~g} \mathrm{NaCl} / 1)$ was taken up in a syringe, weighed and injected into the cephalic vein. The syringe was reweighed and the exact dose administered was calculated. Blood samples $(10 \mathrm{ml})$ were taken via the cannula at defined times (generally 2, 5, 10, 20,30,60, 90,150 and $180 \mathrm{~min}$ ) after the isotope injection. Blood was collected into plain glass tubes and stored on ice before the serum was separated from the whole blood by centrifugation.

A portion of each serum sample was diluted tenfold with $3 \cdot 1 \mathrm{M}-\mathrm{HNO}_{3}$ and aspirated directly into the atomic absorption spectrometer for determination of total $\mathrm{Zn}$ concentration. The remainder of each serum sample was diluted with a surfactant (Triton $\mathrm{X}-100$ ) and the ${ }^{70} \mathrm{Zn}:{ }^{64} \mathrm{Zn}$ isotope ratios were determined by inductively coupled plasma mass spectrometry (ICP-MS; AEA Analytical Services, Harwell, Oxon). 
Table 1. Zinc balance data for control and enteropathic Irish setters

\begin{tabular}{llcc}
\hline & $\begin{array}{c}\text { Zn intake } \\
(\mathrm{mg} / \mathrm{kg} \\
\text { body wt } \\
\text { per d) }\end{array}$ & $\begin{array}{c}\text { Zn output } \\
(\mathrm{mg} / \mathrm{kg} \\
\text { per d) }\end{array}$ & $\begin{array}{c}\text { Balance } \\
(\mathbf{m g} / \mathrm{kg} \\
\text { per d) }\end{array}$ \\
\hline Control & & & \\
A & 1.31 & 1.51 & -0.20 \\
B & 1.00 & 1.12 & -0.12 \\
C & 1.40 & 1.42 & -0.02 \\
D & 1.10 & 1.11 & -0.01 \\
E & 0.60 & 0.62 & -0.02 \\
Mean & 1.08 & 1.16 & -0.08 \\
SD & 0.31 & 0.35 & 0.08 \\
Enteropathic & & & \\
G & 1.42 & 1.51 & -0.09 \\
H & 1.41 & 1.68 & -0.27 \\
I & 0.56 & 0.70 & -0.14 \\
J & 0.55 & 0.53 & 0.02 \\
K & 1.09 & 1.31 & -0.22 \\
L & 1.15 & 1.14 & 0.01 \\
Mean & 1.03 & 1.15 & -0.11 \\
SD & 0.36 & 0.41 & 0.11 \\
\hline
\end{tabular}

\section{Balance study}

After the kinetic study had been completed the dogs were placed in individual stainless steel metabolism cages. A faecal marker (carmine red) was given along with the first and after the last meal of a $48 \mathrm{~h}$ balance period. Faecal samples were collected from (and including) the first appearance of the carmine marker in the stool until (but not including) the appearance of the second marker. Complete urine collections were made throughout the balance period. The volume of urine collected was measured and a portion acidified with $1 \mathrm{ml}$ concentrated $\mathrm{HCl}$ per $100 \mathrm{ml}$ urine and retained. Urine $\mathrm{Zn}$ content was determined by direct aspiration into an atomic absorption spectrometer. Faecal samples were weighed and homogenized, and a portion was wet-ashed in concentrated $\mathrm{HNO}_{3}$. After dilution with deionized distilled water the $\mathrm{Zn}$ content was determined by atomic absorption spectrometry.

Weighed portions of meat and cereal mixer were given separately twice daily (morning and evening); any meat or cereal not eaten was weighed and total food intake calculated.

Student's $t$ test was used for statistical comparisons.

\section{RESULTS}

The body weights of the control dogs were higher than those with enteropathy (control 29.9 (sD 2.8) $\mathrm{kg} v$. enteropathic 21.1 (SD 1.7) $\mathrm{kg}$ ). Dietary $\mathrm{Zn}$ intake, total $\mathrm{Zn}$ output and the resulting balance for $\mathrm{Zn}$ are shown in Table 1 . These show no differences between the two groups when the effects of body weight are taken into consideration and the overall balance was not significantly different from zero for either group. Serum $\mathrm{Zn}$ concentrations were unchanged in the enteropathic group compared with the control animals (control 13.2 (SD 0.9) $\mu \mathrm{mol} / 1 v$. enteropathic 13.2 (SD 0.7) $\mu \mathrm{mol} / \mathrm{l}$ ).

An example of the decay of ${ }^{70} \mathrm{Zn}$ enrichment in the plasma of a control dog following intravenous injection is shown in Fig. 1. Analysis of this curve by computer regression ('Regression', Blackwell Scientific Software) revealed that it was composed of two 


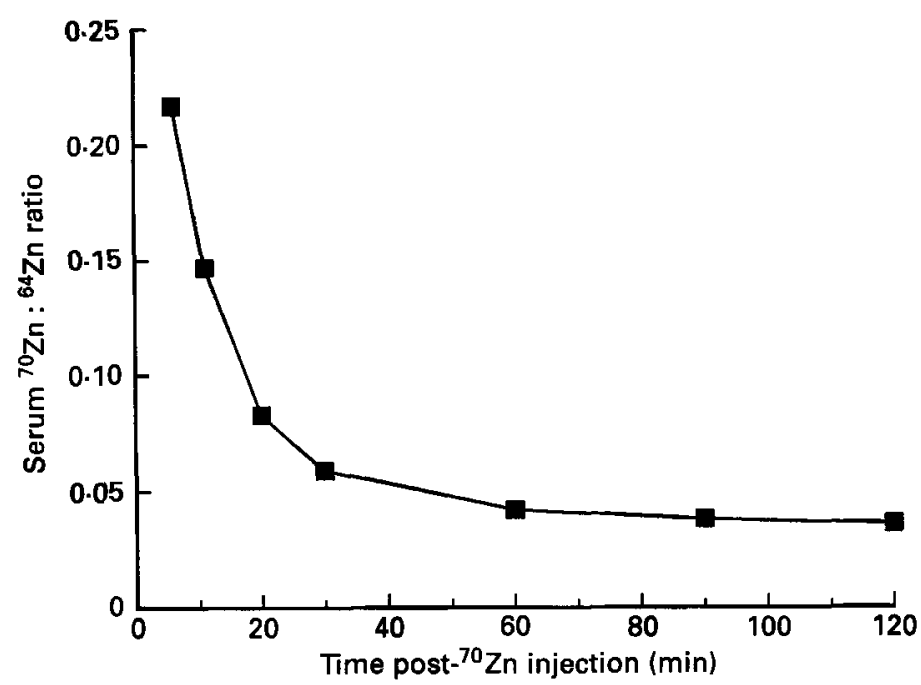

Fig. 1. Changes in serum ${ }^{70} \mathrm{Zn}:{ }^{64} \mathrm{Zn}$ ratio with time following injection of $0.25 \mathrm{Mg}{ }^{70} \mathrm{Zn}(96.5 \%)$ in a healthy Irish setter. For details of procedures, see p. 70.

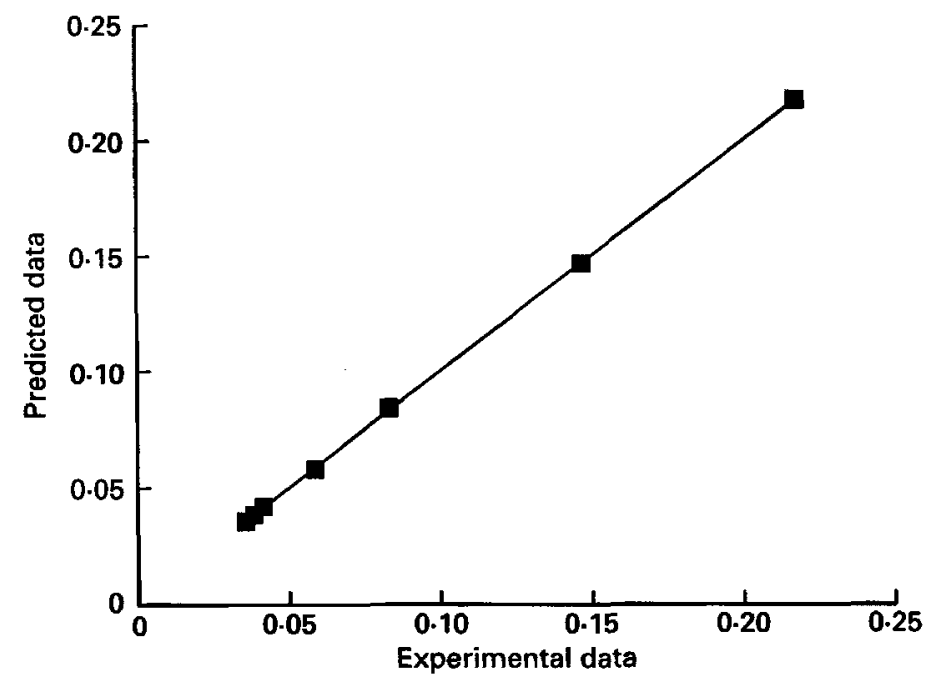

Fig. 2. Correlation between actual serum ${ }^{70} \mathrm{Zn}:{ }^{64} \mathrm{Zn}$ ratio in Irish setters and data predicted from the derived decay equation: $Y=0.322 \mathrm{e}^{-0 \cdot 1068 \mathrm{t}}+0.048 \mathrm{e}^{-0 \cdot 0026 \mathrm{t}}$. The relationship is described by the equation: $Y=0.99939 x+0 \cdot 00002$ (r 0.999).

exponential functions and therefore followed two-compartment kinetics. The twocompartment equations derived from these data were then used to predict the data at different time points and a correlation between predicted and actual data is shown in Fig. 2. This indicates the quality of the 'fit' of the data to the derived equation.

Using the techniques described by Shipley \& Clark (1972) as applied to studies of $\mathrm{Zn}$ isotope ratios by Lowe et al. (1991, 1993), a two-compartment model was used to describe the removal of isotope from the bloodstream. The model represents two metabolic compartments of $\mathrm{Zn}$, designated pool (a) and pool (b), with which $\mathrm{Zn}$ can rapidly exchange 
(a)

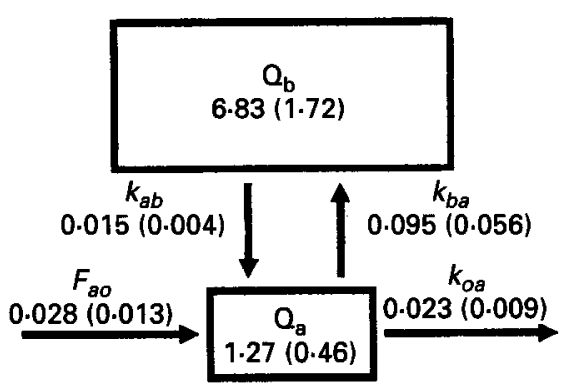

(b)

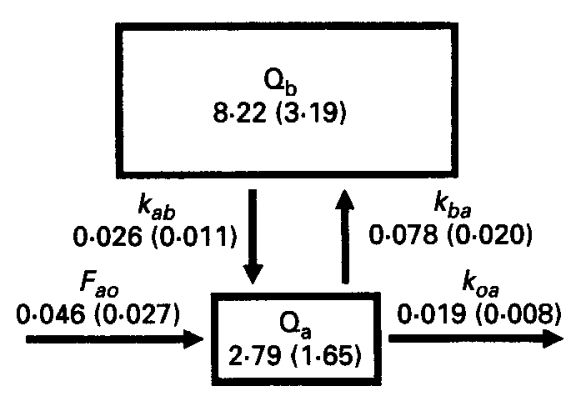

Fig. 3. (a) Schematic representation of the two-compartment model of serum zinc kinetics showing the initial $\left(\mathrm{Q}_{\mathrm{a}}\right)$ and second $\left(Q_{b}\right)$ pools $(\mu \mathrm{mol} / \mathrm{kg})$ with which intravenously injected ${ }^{70} \mathrm{Zn}$ equilibrated in control Irish setters. The fractional rates of transfer/min of $\mathrm{Q}_{\mathrm{a}}$ to $\mathrm{Q}_{\mathrm{b}}\left(k_{a b}\right.$ and $\left.k_{b a}\right)$ and from $\mathrm{Q}_{\mathrm{a}}$ out of the system $\left(k_{o a}\right)$ are shown together with the calculated flow of zinc into $\mathrm{Q}_{\mathrm{B}}$ from outside of the model system $\left(F_{a,}, \mu \mathrm{mol} / \mathrm{kg}\right.$ per min). Values are shown as means with their standard deviations in parentheses. $(b)$ Calculated sizes of exchangeable pools and fractional turnover rates for enteropathic Irish setters treated in the same way as control dogs.

and which are the primary contributors to the kinetics observed over the time period studied. The calculated size of the initial pool with which the ${ }^{70} \mathrm{Zn}$ equilibrated $\left(Q_{\mathrm{a}}\right)$, the size of the second exchangeable pool $\left(\mathrm{Q}_{\mathrm{b}}\right)$ together with the flux of $\mathrm{Zn}$ into pool (a) $\left(F_{a 0}\right)$ and the fractional turnover rates between the pools for the control dogs is shown in Fig. $3(a)$. The calculated sizes of pools (a) and (b) for the enteropathic dogs are shown in Fig. 3(b) and Table 2. The mean value of $\mathrm{Q}_{\mathrm{a}}$ was significantly greater in the enteropathic group compared with the controls, although the individual data indicate that only three of the enteropathic dogs $(J, K$ and $L)$ had elevated $Q_{a}$ values, the remaining three having $Q_{a}$ values that fell within the control range (Table 2). There was no significant difference in the mean size of pool (b) between the two groups; however, the individual data again show that $\mathrm{J}$, $K$ and $L$ had elevated $Q_{b}$ values. There were no significant differences between the two groups for fractional transfer rates between the pools (Fig. 3), but the higher amounts of $\mathrm{Zn}$ in pools (a) and (b) in the three enteropathic dogs ( $\mathrm{J}, \mathrm{K}$ and $\mathrm{L}$ ) were accompanied by a higher rate of flux between pools (b) and (a) (i.e. $k_{a b} \times \mathrm{Q}_{\mathrm{b}}$ ). 
Table 2. Size of exchangeable pools of zinc $(Q)$ in enteropathic dogs

\begin{tabular}{lcc}
\hline & $\begin{array}{c}\mathrm{Q}_{\mathrm{a}} \\
(\mu \mathrm{mol} / \mathrm{kg})\end{array}$ & $\begin{array}{c}\mathrm{Q}_{\mathrm{b}} \\
(\mu \mathrm{mol} / \mathrm{kg})\end{array}$ \\
\hline $\mathrm{G}$ & 1.56 & 6.44 \\
$\mathrm{H}$ & 1.39 & 4.93 \\
$\mathrm{I}$ & 1.27 & 6.01 \\
$\mathrm{~J}$ & 5.34 & 13.39 \\
$\mathrm{~K}$ & 3.72 & 10.52 \\
$\mathrm{~L}$ & 3.48 & 8.05 \\
$\mathrm{Mean}$ & $2.79^{*}$ & 8.22 \\
SD & 1.65 & 3.19 \\
& & \\
Control values & 1.27 & 6.83 \\
Mean & 0.46 & 1.72 \\
\hline
\end{tabular}

* Mean value was significantly different from that of control animals $(P<0-05)$.

\section{Precision of calculated variables}

The precision with which the variables derived from the kinetic decay data can be calculated is dependent upon the quality of ' $\mathrm{fit}$ ' of the exponential decay curve to the experimental data (Figs. 1 and 2) and of the assumptions which are necessary for the calculation of the derived variables. Thus the average coefficient of variation of the values of $Q_{a}$ in Table 2 was found to be $3.8 \%$, but that for $Q_{b}$ was $32.7 \%$. Considerably more confidence can therefore be placed in the derived values for $\mathrm{Q}_{\mathrm{a}}$ and $k_{b a}$ than on the other variables. However, this cannot explain the apparent differences in the values derived for $Q_{a}$ and $Q_{b}$ for dogs $J, K$ and $L$. The quality of the 'fit' of the regression curve to the data for these three animals was not significantly different from that for the other animals.

\section{DISCUSSION}

The short-term decay of isotopic $\mathrm{Zn}$ in the dog appears to follow closely the twocompartment kinetics demonstrated in previous studies over similar time periods in the rat (Lowe et al. 1991) and man (Lowe et al. 1993). Detailed studies in the rat using radioactive ${ }^{65} \mathrm{Zn}$ have clearly indicated the applicability of this two-compartment model over this time period and although studies of such detail are not possible using stable isotopes the data obtained indicate that similar kinetics apply in the dog. Investigation into the physiological location of the two metabolic pools in the rat indicated that pool (a) was composed of plasma $\mathrm{Zn}$ and pool (b) was composed of a portion of the liver $\mathrm{Zn}$. The model used for analysis of the two-compartment decay equation takes into account this probable anatomical distribution of the two putative pools, i.e. it assumes that any ${ }^{70} \mathrm{Zn}$ redistributing from pool (b) (a liver Zn pool) must re-enter pool (a) (the plasma) before transfer to other sites (Shipley \& Clark, 1972). The sizes of these pools, when expressed on a body-weight (kg) basis, are remarkably similar in the rat and man (pool (a) rat 0.703 (sE 0.05), man 0.720 (SE 0.102) $\mu \mathrm{mol} / \mathrm{kg}$; pool (b) rat 2.939 (SE 1.194), man 3.600 (SE 0.929) $\mu \mathrm{mol} / \mathrm{kg}$ ). If plasma volume in litres is taken to be $5 \%$ body weight, in the rat and human the $\mathrm{Zn}$ in pool (a) can be accounted for by serum $\mathrm{Zn}$ alone. This is not the case in the dog. The present study reveals that the sizes of both pools (a) and (b) are greater in the dog per $\mathrm{kg}$ body weight (Fig. 3). If the serum volume is taken to be $5 \%$ body weight of the control group (i.e. $50 \mathrm{ml} / \mathrm{kg}$ ), and the mean serum $\mathrm{Zn}$ concentration is $13.4 \mu \mathrm{mol} / 1$, it is clear that pool (a), 
which contains $1.27 \mu \mathrm{mol} \mathrm{Zn} / \mathrm{kg}$ body weight, cannot be located solely in the serum. This implies that pool (a) must include non-serum sources of $\mathrm{Zn}$ with which plasma $\mathrm{Zn}$ can exchange rapidly.

The two-compartment model is fully compatible with more complex models of $\mathrm{Zn}$ metabolism (Wastney et al. 1986; Fairweather-Tait et al. 1993; Miller et al. 1994). It is clearly not an exact representation of the physiological fluxes of isotope which occur following injection and further useful information might be obtained from protocols involving greater frequency or duration of sampling and more complex modelling (Fairweather-Tait et al. 1993). However, previous studies have indicated the potential relevance of this simple model both in terms of the anatomical distribution of the exchangeable pools and their response to $\mathrm{Zn}$ deficiency (Lowe et al. 1991).

In the rat the sizes and turnover rates of these metabolic pools are lower in $\mathrm{Zn}$-deficient animals than controls (Lowe et al. 1991), but no evidence for a similar decline was seen here. In fact the size of $Q_{a}$ was significantly increased in three of the enteropathic animals. This implies an expansion of the extracellular space in these animals. We are unsure of the reason for this, but speculate that an immune reaction to the presence of gluten in the small intestine may result in an increase in extracellular space due to an increase in membrane permeability (Cousins \& Leinart, 1988). Such a hypothesis is supported by studies of intestinal permeability in these animals (Hall \& Batt, 1991).

Enteropathic animals were significantly smaller than those in the control group, but even when the sizes of pools (a) and (b) are expressed in absolute terms there is still a marked increase in the size of pool (a). An expansion of this pool was also unexpectedly observed in human subjects with alcoholic liver disease (Lowe et al. 1993). It is therefore possible that an expansion of pool (a) may be a relatively non-specific effect of disease in man and animals, but further studies will be required to clarify this.

Plasma $\mathrm{Zn}$ concentrations in the enteropathic group were not significantly different from those of control animals and balance results did not indicate any gross loss or accumulation of $\mathrm{Zn}$. Taken together with the kinetic data these results do not appear to indicate a reduction in $\mathrm{Zn}$ status in these animals.

We are unable to explain the apparent differences between the short-term $\mathrm{Zn}$ kinetics in three of the enteropathic animals (J, K and L) compared with the others (Table 2). There was no clinical indication that these animals were markedly different from the other diseased dogs, nor was there any relationship between $Q_{a}$ or $Q_{b}$ and e.g. plasma $Z n$ concentration, dietary $\mathrm{Zn}$, age or sex.

In summary it does not appear that gluten-sensitive enteropathy in Irish setters results in low $\mathrm{Zn}$ status. There is no significant difference in $\mathrm{Zn}$ balance or plasma $\mathrm{Zn}$ concentration between healthy and enteropathic dogs. In addition the observed expansion and concurrent increase in $\mathrm{Zn}$ flux between the rapidly exchanging $\mathrm{Zn}$ pools in some enteropathic animals indicate changes in $\mathrm{Zn}$ metabolism which are not consistent with the effects of $\mathrm{Zn}$ deficiency.

Financial support from the Wellcome Trust (grant no. 17862/1.5) is gratefully acknowledged.

\section{REFERENCES}

Cousins, R. J. \& Leinart, A. S. (1988). Tissue specific regulation of zinc metabolism and metallothionein gene by interleukin 1. FASEB Journal 2, $2884-2890$.

Dunn, M. R. A. \& Cousins, R. J. (1989). The kinetics of zinc metabolism in the rat: effect of dibutyryl cAMP. American Journal of Physiology 256, E420-E430.

Fairweather-Tait, S., Jackson, M. J., Fox, T. E., Wharf, S. G., Eagles, J. \& Croghan, P. (1993). The measurement of exchangeable pools of zinc using the stable isotope ${ }^{70} \mathrm{Zn}$. British Journal of Nutrition 70, 221-234. 
Foster, D. M., Aamodt, R. L., Henkin, R. I. \& Berman, M. (1979). Zinc metabolism in humans: a kinetic model. American Journal of Physiology 273, R340-R349.

Golden, M. H. N. (1989). The diagnosis of Zn deficiency. In Zinc in Human Biology, pp. 323-334 [C. F. Mills, editor]. London: Springer-Verlag.

Hall, E. J. \& Batt, R. M. (1990a). Development of wheat-sensitive enteropathy in Irish setters: morphologic changes. American Journal of Veterinary Research 51, 978-982.

Hall, E. J. \& Batt, R. M. (1990b). Development of wheat-sensitive enteropathy in Irish setters: biochemical changes. American Journal of Veterinary Research 51, 983-989.

Hall, E. J. \& Batt, R. M. (1991). Abnormal permeability precedes the development of a gluten-sensitive enteropathy in Irish Setter dogs. Gut 32, 749-753.

Hall, E. J. \& Batt, R. M. (1992). Dietary modulation of gluten sensitivity in a naturally occurring enteropathy of Irish setter dogs. Gut 33, 198-205.

Hallbrook, T. \& Hedelin, H. (1977). Zine metabolism and surgical trauma. British Journal of Surgery 64, $271-273$.

Hawkins, T., Marks, J. M., Plummer, V. M. \& Greaves, M. W. (1976). Whole body monitoring and other studies of zinc-65 metabolism in patients with dermatological diseases. Clinical and Experimental Dermatology 1 , 243-252.

Henkin, R. I., Foster, D. M., Aamodt, R. L. \& Berman, H. (1984). Zinc metabolism in adrenal cortical insufficiency: effects of carbohydrate-active steroids. Metabolism 33, 491-501.

Jackson, M. J., Giugliano, R., Giugliano, L. G., Oliveira, E. F., Shrimpton, R. \& Swainbank, I. G. (1988). Stable isotope metabolic studies of zinc nutrition in slum-dwelling, lactating women in the Amazon Valley. British Journal of Nutrition 59, 193-203.

Jackson, M. J., Jones, D. A. \& Edwards, R. H. T. (1982). Tissue Zn levels as an index of Zn status. Clinical Physiology 2, 333-343.

Jackson, M. J., Jones, D. A., Edwards, R. H. T., Swainbank, I. G. \& Coleman, M. L. (1984). Zinc homeostasis in man: studies using a new stable isotope-dilution technique. British Journal of Nutrition 51, $199-208$.

Lowe, N. M., Bremner, I. \& Jackson, M. J. (1991). Plasma ${ }^{65} \mathrm{Zn}$ kinetics in the rat. British Journal of Nutrition 65 , 445-455.

Lowe, N. M., Green, A., Rhodes, J. M., Lombard, M., Jallan, R. \& Jackson, M. J. (1993). Studies of human Zn kinetics using the stable isotope ${ }^{70} \mathrm{Zn}$. Clinical Science 84, 113-117.

Lowe, N. M., Rhodes, J. M., Lombard, M. G., Green, A., Jallan, R. \& Jackson, M. J. (1992). Short term Zn kinetics in normal subjects and patients with alcoholic liver disease. FASEB Journal 6, A1087.

Miller, L. V., Hambidge, K. M., Naake, V. L., Hong, Z., Westcott, J. L. \& Fennessey, P. V. (1994). Size of the zinc pools that exchange rapidly with plasma zinc in humans: alternative techniques for measuring and relations to dietary zinc intake. Journal of Nutrition 124, 268-276.

Shipley, R. A. \& Clark, R. E. (1972). Tracer Methods For 'In Vivo' Kinetics. New York: Academic Press.

Wastney, M. E., Aamodt, R. L., Rumble, W. F. \& Henkin, R. I. (1986). Kinetic analysis of Zn metabolism and its regulation in normal humans. American Journal of Physiology 251, R398-R408. 